\title{
Analysis of Big Data in Healthcare Applications
}

\author{
S. Sadagopan, R.Muthu Venkata Krishnan, B.Sundarraj, S.Sri Gowtham
}

\begin{abstract}
As of late, tremendous fields of sorted out, unstructured, and semi-composed data have been made by various foundations around the world and this heterogeneous data all in all implied as enormous data. The prosperity business section has been portrayed by the need to manage the enormous data being made by various sources, which are remarkable for conveying high volumes of heterogeneous data. Distinctive huge data examination gadgets and frameworks have been created for dealing with these monstrous proportions of data, in the human administrations portion. This paper discusses the impact of gigantic data in human administrations, and various gadgets accessible in the Hadoop organic framework for dealing with it. We furthermore explore the hypothetical plan of colossal data examination for social protection which incorporates the data gathering history of different branches, the genome database, electronic prosperity records, content/imagery and clinical decisions sincerely steady system.
\end{abstract}

Key words:Big data, Healthcare, Hadoop,MapReduce.

\section{INTRODUCTION}

Reliably, data is delivered by a gathering of different applications, devices, and geographical research practices for the purposes behind atmosphere guaging, atmosphere estimate, disaster evaluation, bad behavior revelation, and the heath business, to give a few models. In current situation, gigantic data is connected with focus headways and various undertakings including Google, Facebook, and IBM, which expel regarded information from the enormous volumes of data assembled. Colossal data is being made rapidly in each field including social protection, with respect to understanding thought, uninvolved assent, and diverse authoritative necessities. As the overall masses continues extending nearby the human future, treatment movement multiplications are growing quickly, and a part of the decisions principal these fast changes must be established on data.

Human administrations speculators are ensured with new gaining from immense data, indicated both for its volume similarly as its complexity and range. Pharmaceutical-industry experts and financial specialists have begun to routinely inspect tremendous data to procure vision, yet these activities are still before all else times and ought to be synchronized to address restorative

Revised Manuscript Received on July 22, 2019.

S. Sadagopan, Department of CSE, Bharath Institute of Higher Education and Research, Chennai, Tamilnadu, India.

R.Muthu Venkata Krishnan, , Department of CSE, Bharath Institute of Higher Education and Research, Chennai, Tamilnadu, India

B.Sundarraj Department of CSE, Bharath Institute of Higher Education and Research, Chennai, Tamilnadu, India

S. Sri Gowtham Department of CSE, Bharath Institute of Higher Education and Research, Chennai, Tamilnadu, India. administrations transport issues and improve human administrations quality. Early structures for gigantic data examination of social protection informatics have been seen across over various circumstances, e.g., the examination of patient characteristics and confirmation of treatment cost and results to locate the best and most monetarily clever meds.

Prosperity informatics is portrayed as the mix of human administrations sciences, figuring sciences and information sciences in the examination of social protection information. Prosperity informatics joins data verifying, amassing, and recuperation to give increasingly profitable results by therapeutic administrations providers. In the social protection structure, data is set apart by its heterogeneity and collection in light of the interfacing of a varying extent of biomedical data bases including, for example, sensor data, imagery, quality groups, look into office tests, free substance, and economics. Most data in social protection system (e.g., authority's notes, lab test outcomes, and clinical data) is unstructured and isn't stowed electronically, i.e., it exists just in printed duplicates and its volume is growing in all regards rapidly.

At this moment, there is rule base on the digitization of these colossal supplies of printed duplicate data. The uprisings of data measure are truly making an issue to achieve this goal. The various wordings and models that have been made to decide the issues related with gigantic data revolve around handling four issues known as the four Vs, specifically: volume, arrangement, speed, and veracity. The various classes of data in human administrations applications consolidate Electronic Health Records (EHR), machine delivered/sensor data, prosperity information exchanges, calm libraries, entryways, Genetic databases, and open records. Open records are noteworthy wellsprings of colossal data in the restorative administrations business and require capable data examination to decide their related human administrations issues.

A report by McKinsey Global Institute recommends that use colossal data imaginatively and feasibly. Recorded systems to remedial research have generally focusedabout the examination of contaminated states subject to the alterations in physiology as a checked observation on specific arrangement of data.

\section{MATERIALS AND METHODOLOGY}

In this paper, variousregions of huge data examination in prescription are given. They don't thoroughly reflect the uses of monstrous data 
examination in medicin esomewhat they are wanted to contribute a point of perspective on far reaching, unmistakable area so investigate where the thoughts of immense data examination are starting at now being related. Clinical image handling in clinicaldataset are an imperative wellspring of information every now and again utilized for conclusion, treatment evaluation and arranging. Such information requires extensive capacity limits whenever put away long haul.

It additionally desiresrapid and exact estimations if somedecision helps to execute the information. Likewise, if varioussources of datasets obtained fromeach patient are additionally used during the determinations, guesses and treatment methods.

Investigations of logical marks are frequently growingwhen realistic along with situational setting mindfulness that must be implanted into the improvement of ceaseless observing and perceptivemodels to assurance its adequacy and power.

The integrated informations for every human profile are consolidated and different vast throughput procedures for genome sequencing to produce an inside and out wellbeing and infection conditions of a subject. Atlast, acknowledging activity capable recognitions at the medical domains.

In spite of the gigantic use devoured by the present medicinal services frameworks, clinical results remain problematic, especially in the United States, where 96 individuals for each beyond words from conditions thought about treatable. A key factor ascribing towards such wasteful aspects is the failure to adequately accumulate, offer and use data in an increasingly complete way inside the medicinal services frameworks.

This is an open door for huge information investigation to assume an increasingly huge job in supporting the investigation and disclosure process, improving the conveyance of consideration, structuring and plan social insurance arrangement, giving a way to completely estimating and assessing the confused and tangled information of human services. All the more significantly, reception of bits of knowledge picked up from huge information investigation can possibly spare lives, improve care conveyance, extend access to human services, adjust pay to execution, and help control the vexing development of social insurance costs.

\section{A. Clinical Dataset processingin theview of Big Data}

Clinical imaging contributes critical information on life constructions and organs. Additionally, it is utilized for organ outline, distinguishing tumors in lungs, spinal distortion determination, conduit stenosis location, aneurysm identification, and so on. Image processing techniques such as, enhancement, partition and de-noising and furthermore AI techniques are employed.

\section{B. Data Produced by Imaging Techniques}

Clinical imaging fuses a widespreadseries of differentdataset procurement procedures normally employed for anvariety of clinical domains.

The innovative goals and depths of those images create expansive volumes of dataset requiring superior figuring and improved investigative strategies for its use.

The coordination of pictures in various modalities and additionally other medical and physiological datasetcanincrease the precision of analysis and result expectation of sickness. Liebeskind and Feldman investigated enhancements in neurovascular imaging and the job of multi-modal dataset including angiography and perfusion imaging for assessing the cerebrum vascular turmoil, and accomplishing exactness medication. Postponed improved MRI is utilized for careful appraisal of myocardial localized necrosis scar and electro anatomic mapping could help in distinguishing the sub endocardial expansionThe activity of studying multi-modular pictures to manufacture the accuracy of finding in perceiving the proximity of deteriorations and osteophytes in the temporomandibular joint (TMJ) is looked into by Hussain et al.

\section{Big data in Healthcare}

The limit of restorative imageries is rising .

While utilizing data at an area/institutional measurement, a fundamental piece of the examination is on how the made system is surveyed and endorsed. Taking remarked on data or a composed method to remark on new data is a real test. This turns out to be much more provocative when substantial scale information mix from different establishments is considered. For similar applications and a similar methodology, for example, CT examines for horrendous cerebrum damage, distinctive organizations may utilize diverse settings for picture acquisitions.

So as to help the multimodal pictures and their reconciliation with other restorative information, new systematic techniques with ongoing possibility and adaptability are required.

\section{Analytical Methods}

The target of restorative image dataset examination has to propel the interpretability of delineated matter. Different methods and structures are building up for clinical image preparing. In any case, these methods are not basically relevant for huge information investigation.

- Employing an outstanding AI technique, bolster vector machines (SVM), to discover ideal parameter for lung surface characterization.

- Content based clinical image sequencing.

-Wavelet representation for characterization.

The crossover AI methodshave been adoptedto characterize schizophrenia patients and solid controls employing resonance imaging and single nucleotide polymorphism information. An order precision of $87 \%$ has been accomplished which is higher than utilizing either information alone.

Tsymbal et al. developed a medical imaging model that investigates discriminative separation training with essentially lower computational intricacy contrasted with established choices and subsequently this framework is progressively adaptable to recovery from enormous information 


\section{RESULTS AND DISCUSSIONS}

If Further, making indicative methods, tries have been made for social event, uniting, relegating and anonymizing therapeutic data. One model is iDASH (consolidating data for examination, anonymization, and sharing) which is a focal point for biomedical processing.It highlight reliant on the figuring and gadgets for sharing data in a security ensuring way.

\section{A. Collecting, Sharing and Compressing Methods}

In light of Hadoop stage, a framework has been intended for swapping, putting away and sharing electronic restorative records (EMR) among various social insurance frameworks. This framework can likewise enable clients to recover restorative pictures from a database. Medicinal information has been reviewed from an obtaining perspective where patients' imperative information is gathered through a system of sensors. This framework conveys information to a cloud for capacity, conveyance and preparing. A model framework has been executed in to deal with standard demands on a database of Digital Imaging and Communications in Medicine (DICOM) images. This plan utilizes Microsoft Windows Azure as a distributed computing stage.

When managing huge volume of information, pressure procedures can beat information stockpiling and system transmission capacity confinements. Numerous methodologies have been produced for medicinal picture pressure. In any case, there are a couple of strategies being produced for enormous information pressure. A strategy has been intended to pack both high throughput ordering and information created by count of log chances of likelihood mistake for every nucleotide while the most extreme pressure proportionshas been accomplished separately.

Theimage dataset is restorative and medical information checking genotyping, quality articulation, and proteomic estimations with socioeconomics, research center qualities, pictures, helpful mediations. By embodying the information with a diagram demonstrate, a structure for investigating huge scale information has been introduced. In this method, the principal flag handling strategies, for example, separating and Fourier change are impelled. In the introduction of straightforwardness and power hypothesis of knowledge in enormous informations have been explored. The objective of Straightforwardness Power hypothesis is to rearrange and as comparable ideas from numerous fields, for example, man-made consciousness, standard processing, science, and human observation and discernment that can be seen as a cerebrum like framework. The proposed framework achieves lossless pressure through the coordinating and unification of examples. Notwithstanding, this framework is quiet in structure organize and can't be upheld by current innovations.

There are a few confinements in actualizing the application explicit pressure strategies on both broadly useful processors and parallel processors, for example, designs preparing unitsas those calculations essential very factor control and complex piece controls which are not appropriate to parallel processors and pipeline models.

\section{B. Signal Analysis on Big Data}

Research in flag handling for advancing huge information based clinical choice emotionally supportive networks is getting progressively common. Indeed associations. A tremendous measure of information in brief timeframe is created in serious consideration units where huge volumes of physiological information are procured from every patient. Subsequently, the potential for creating clinical choice supportive network system in brief timeframe is created in serious consideration units. An ascendable framework for building up a patient consideration the board framework is presented, which consolidates static information and stream information checked from basically sick patients in the intensive care unit for information mining and alarming restorative condition of basic occasions continuously.

In like manner, Bressan et al. built up a design specific for a neonatal, which is used in gushing information from mixture siphons, EEG screens, cerebral oxygenation screens, and so on to manage the cost of clinical choice help. A clinical preliminary is as of now in progress which removes biomarkers through flag preparing from heart and respiratory waveforms continuously to test in the case of maintaining stable pulse and respiratory rate inconstancy all through the unconstrained breathing preliminaries, is managed to patients before extubation, may foresee consequent fruitful extubation. A creature contemplate demonstrates how securing of noninvasive constant information, for example, tissue oxygenation, liquid substance and blood stream can be utilized as markers of delicate tissue recuperating in wound consideration. Electrocardiograph parameters from telemetry alongside statistic data including restorative history, launch division, research facility esteems, and meds have been utilized to build up an in clinic early recognition framework for heart failure.

An investigation exhibited by Lee et al. utilizes the MIMIC II database to provoke remedial obstruction to hypotensive occurrences utilizing heart and pulse time arrangement information. Another examination exhibits the utilization of physiological waveform information alongside clinical information from the database for discovering similitudes. This closeness can help parental figures in the basic leadership process while using results and medications information assembled from comparative ailment cases from an earlier time. An amalgamation of numerous waveform data accessible in the database has been used to grow early discovery of cardiovascular shakiness. Numerous classes of physiological information caught in the usable and pre-employable consideration settings and how investigation can devour these information to supportcontinuously screen the status of the patients, when medical procedure are portrayed in.

The extension of multimodality observing for awful mind damage patients and exclusively custom fitted, tolerant explicit consideration are analyzed in. The originations of multimodal checking for optional mind damage in neuro-basic consideration just as layout introductory and 
future methodologies utilizing informatics instruments for comprehension and applying such information towards clinical consideration are portrayed in.

Nonetheless, comparable to clinical applications, consolidating data all the while gathered from various convenient gadgets can end up testing. Pantelopoulos et al. discussed the innovative work of wearable biosensor frameworks and recognize the focal points and weaknesses around there of study.

So also, convenient and related electrocardiogram, circulatory strain and body weight gadgets are utilized to setup a system based investigation of telemedicine. The decent variety of fixed just as portable sensors accessible for information mining in the human services part and how such information can be utilized for creating understanding consideration innovations are overviewed in.

\section{CONCLUSION}

Huge information investigation which use huge numbers of dissimilar, organized and unstructured information sources is going to assume an essential job in medicinal services is polished later on. Arrays of researches havebeendone forsupporting in simple control and execution of social protection staff and patients. Here we concentrated on restorative imageanalysis, preparing and joining of physiological information with genomic information.

\section{REFERENCES}

[1] Kumaravel A., Rangarajan K.,Algorithm for automaton specification for exploring dynamic labyrinths,Indian Journal of Science and Technology,V-6,I-SUPPL5,PP-4554-4559,Y-2013

[2] P. Kavitha, S. Prabakaran "A Novel Hybrid Segmentation Method with Particle Swarm Optimization and Fuzzy C-Mean Based On Partitioning the Image for Detecting Lung Cancer" International Journal of Engineering and Advanced Technology (IJEAT) ISSN: 2249-8958, Volume-8 Issue-5, June 2019

[3] Kumaravel A., Meetei O.N.,An application of non-uniform cellular automata for efficient cryptography,2013 IEEE Conference on Information and Communication Technologies, ICT 2013,V-,I-,PP-1200-1205,Y-2013

[4] Kumarave A., Rangarajan K.,Routing alogrithm over semi-regular tessellations,2013 IEEE Conference on Information and Communication Technologies, ICT 2013,V-,I-,PP-1180-1184,Y-2013

[5] P. Kavitha, S. Prabakaran "Designing a Feature Vector for Statistical Texture Analysis of Brain Tumor" International Journal of Engineering and Advanced Technology (IJEAT) ISSN: 2249-8958, Volume-8 Issue-5, June 2019

[6] Dutta P., Kumaravel A.,A novel approach to trust based identification of leaders in social networks,Indian Journal of Science and Technology,V-9,I-10,PP--,Y-2016

[7] Kumaravel A., Dutta P.,Application of Pca for context selection for collaborative filtering,Middle - East Journal of Scientific Research,V-20,I-1,PP-88-93,Y-2014

[8] Kumaravel A., Rangarajan K.,Constructing an automaton for exploring dynamic labyrinths,2012 International Conference on Radar, Communication and Computing, ICRCC 2012,V-,I-,PP-161-165,Y-2012

[9] P. Kavitha, S. Prabakaran "Adaptive Bilateral Filter for Multi-Resolution in Brain Tumor Recognition" International Journal of Innovative Technology and Exploring Engineering (IJITEE) ISSN: 2278-3075, Volume-8 Issue-8 June, 2019

[10] Kumaravel A.,Comparison of two multi-classification approaches for detecting network attacks, World Applied Sciences Journal,V-27,I-11,PP-1461-1465,Y-2013

[11] Tariq J., Kumaravel A.,Construction of cellular automata over hexagonal and triangular tessellations for path planning of multi-robots,2016 IEEE International Conference on Computational Intelligence and Computing Research, ICCIC 2016,V-,I-,PP--,Y-2017

[12] Sudha M., Kumaravel A.,Analysis and measurement of wave guides using poisson method,Indonesian Journal of Electrical Engineering and Computer Science,V-8,I-2,PP-546-548,Y-2017

[13] Ayyappan G., Nalini C., Kumaravel A., Various approaches of knowledge transfer in academic social network,International Journal of Engineering and Technology,V-,I-,PP-2791-2794,Y-2017

[14] Kaliyamurthie, K.P., Sivaraman, K., Ramesh, S. Imposing patient data privacy in wireless medical sensor networks through homomorphic cryptosystems 2016, Journal of Chemical and Pharmaceutical Sciences 92.

[15] Kaliyamurthie, K.P., Balasubramanian, P.C. An approach to multi secure to historical malformed documents using integer ripple transfiguration 2016 Journal of Chemical and Pharmaceutical Sciences 9

[16] A.Sangeetha,C.Nalini,"Semantic Ranking based on keywords extractions in the web", International Journal of Engineering \& Technology, 7 (2.6) (2018) 290-292

[17] S.V.GayathiriDevi,C.Nalini,N.Kumar,"An efficient software verification using multi-layered software verification tool "International Journal of Engineering \& Technology, 7(2.21)2018 454-457

[18] C.Nalini,ShwtambariKharabe,"A Comparative Study On Different Techniques Used For Finger - Vein Authentication", International Journal Of Pure And Applied Mathematics, Volume 116 No. 82017 , 327-333, Issn: 1314-3395

[19] M.S. Vivekanandan and Dr. C. Rajabhushanam, "Enabling Privacy Protection and Content Assurance in Geo-Social Networks", International Journal of Innovative Research in Management, Engineering and Technology, Vol 3, Issue 4, pp. 49-55, April 2018.

[20] Dr. C. Rajabhushanam, V. Karthik, and G. Vivek, "Elasticity in Cloud Computing", International Journal of Innovative Research in Management, Engineering and Technology, Vol 3, Issue 4, pp. 104-111, April 2018.

[21] K. Rangaswamy and Dr. C. Rajabhushanamc, "CCN-Based Congestion Control Mechanism In Dynamic Networks", International Journal of Innovative Research in Management, Engineering and Technology, Vol 3, Issue 4, pp. 117-119, April 2018.

[22] Kavitha, R., Nedunchelian, R., "Domain-specific Search engine optimization using healthcare ontology and a neural network backpropagation approach", 2017, Research Journal of Biotechnology, Special Issue 2:157-166

[23] Kavitha, G., Kavitha, R., "An analysis to improve throughput of high-power hubs in mobile ad hoc network" ,2016, Journal of Chemical and Pharmaceutical Sciences, Vol-9, Issue-2: 361-363

[24] Kavitha, G., Kavitha, R., "Dipping interference to supplement throughput in MANET", 2016, Journal of Chemical and Pharmaceutical Sciences, Vol-9, Issue-2: 357-360

[25] Michael, G., Chandrasekar, A.,'Leader election based malicious detection and response system in MANET using mechanism design approach", Journal of Chemical and Pharmaceutical Sciences(JCPS) Volume 9 Issue 2, April - June 2016.

[26] Michael, G., Chandrasekar, A.,"Modeling of detection of camouflaging worm using epidemic dynamic model and power spectral density", Journal of Chemical and Pharmaceutical Sciences(JCPS) Volume 9 Issue 2, April - June 2016.

[27] Pothumani, S., Sriram, M., Sridhar, J., Arul Selvan, G., Secure mobile agents communication on intranet,Journal of Chemical and Pharmaceutical Sciences, volume 9, Issue 3, Pg No S32-S35, 2016

[28] Pothumani, S., Sriram, M., Sridhar , Various schemes for database encryption-a survey, Journal of Chemical and Pharmaceutical Sciences, volume 9, Issue 3, Pg NoS103-S106, 2016

[29] Pothumani, S., Sriram, M., Sridhar, A novel economic framework for cloud and grid computing, Journal of Chemical and Pharmaceutical Sciences, volume 9, Issue 3, Pg No S29-S31, 2016

[30] Priya, N., Sridhar, J., Sriram, M. "Ecommerce Transaction Security Challenges and Prevention Methods- New Approach” 2016 ,Journal of Chemical and Pharmaceutical Sciences, JCPS Volume 9 Issue 3.page no:S66-S68

[31] Priya, N.,Sridhar,J.,Sriram, M."Vehicular cloud computing security issues and solutions" Journal of Chemical and Pharmaceutical Sciences(JCPS) Volume 9 Issue

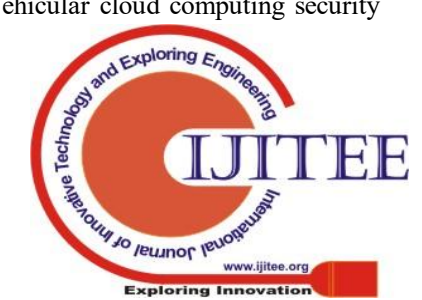


[33] Priya, N., Sridhar, J., Sriram, M. "Mobile large data storage security in cloud computing environment-a new approach" JCPS Volume 9 Issue 2. April - June 2016

[34] Anuradha.C, Khanna.V, "Improving network performance and security in WSN using decentralized hypothesis testing "Journal of Chemical and Pharmaceutical Sciences(JCPS) Volume 9 Issue 2, April - June 2016

[35] Anuradha.C, Khanna.V, "A novel gsm based control for e-devices" Journal of Chemical and Pharmaceutical Sciences(JCPS) Volume 9 Issue 2, April - June 2016.

[36] Anuradha.C, Khanna.V, "Secured privacy preserving sharing and data integration in mobile web environments " Journal of Chemical and Pharmaceutical Sciences(JCPS) Volume 9 Issue 2, April - June 2016.

[37] Sundarraj, B., Kaliyamurthie, K.P. Social network analysis for decisive the ultimate classification from the ensemble to boost accuracy rates 2016 International Journal of Pharmacy and Technology 8

[38] Sundarraj, B., Kaliyamurthie, K.P. A content-based spam filtering approach victimisation artificial neural networks 2016 International Journal of Pharmacy and Technology 83 .

[39] Sundarraj, B., Kaliyamurthie, K.P. Remote sensing imaging for satellite image segmentation 2016 International Journal of Pharmacy and Technology $8 \quad 3$.

[40] Sivaraman, K., Senthil, M. Intuitive driver proxy control using artificial intelligence 2016 International Journal of Pharmacy and Technology 84.

[41] Sivaraman, K., Kaliyamurthie, K.P. Cloud computing in mobile technology 2016 Journal of Chemical and Pharmaceutical Sciences 92.

[42] Sivaraman, K., Khanna, V. Implementation of an extension for browser to detect vulnerable elements on web pages and avoid click jacking 2016 Journal of Chemical and Pharmaceutical Sciences 92.

\section{AUTHORS PROFILE}

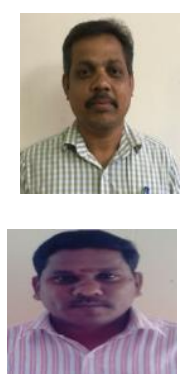

S. Sadagopan, Department of CSE, Bharath Institute of Higher Education and Research, Chennai, Tamilnadu, India.

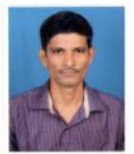

R.MuthuVenkataKrishnan, Assistant Professor, Department of Computer Science \& Engineering, Bharath Institute of Higher Education and Research, Chennai, India

B.Sundarraj, Assistant Professor, Department of Computer Science \& Engineering, Bharath Institute of Higher Education and Research, Chennai, India 